\title{
CORRECTION
}

\section{Correction to: Comparative analysis and physio-biochemical screening of an ex-situ fig (Ficus carica L.) collection}

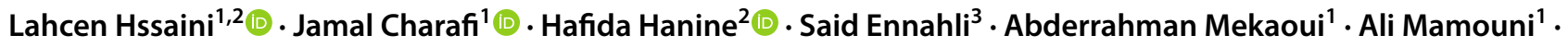 \\ Rachid Razouk ${ }^{1}$ (1)
}

Published online: 11 October 2019

(c) Korean Society for Horticultural Science 2019

\section{Correction to: \\ Horticulture, Environment, and Biotechnology https://doi.org/10.1007/s13580-019-00170-4}

The original version of this article unfortunately contained a mistake. Abderrahman Mekaoui was not listed among the authors. The corrected author list is given above. The original article has been corrected.
Publisher's Note Springer Nature remains neutral with regard to jurisdictional claims in published maps and institutional affiliations.

The original article can be found online at https://doi.org/10.1007/ s13580-019-00170-4.

Rachid Razouk

razouk01@yahoo.fr

1 National Institute for Agricultural Research (INRA), BO 578, Meknes, Morocco

2 Laboratory of Bioprocess and Bio-Interfaces, Faculty of Science and Technology, BO 523, Beni-Mellal, Morocco

3 National School of Agriculture (ENA), BO S/40, Meknes, Morocco 